\begin{tabular}{|c|c|}
\hline \begin{tabular}{|l|} 
Additional \\
Information
\end{tabular} & $\begin{array}{l}\text { NOTICE: This is the author's version of a work that was accepted for } \\
\text { publication in Surface \& Coatings Technology. Changes resulting from } \\
\text { the publishing process, such as peer review, editing, corrections, } \\
\text { structural formatting, and other quality control mechanisms may not be } \\
\text { reflected in this document. Changes may have been made to this work } \\
\text { since it was submitted for publication. A definitive version was } \\
\text { subsequently published in } 206 \text { (18), 2012, doi: } \\
10.1016 / \text { j.surfcoat.2012.03.050 }\end{array}$ \\
\hline \begin{tabular}{|l|} 
Alternative \\
Location
\end{tabular} & http://dx.doi.org/10.1016/j.surfcoat.2012.03.050 \\
\hline
\end{tabular}




\section{Accepted Manuscript}

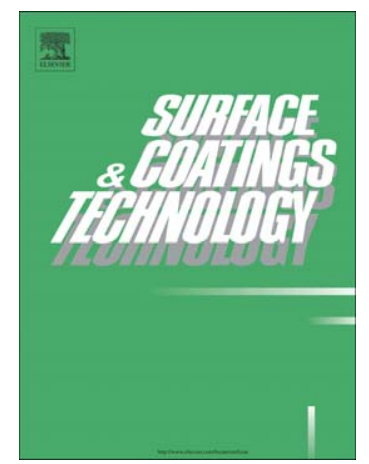

Acoustic emission analysis on tensile failure of air plasma-sprayed thermal barrier coatings

W.B. Yao, C.Y. Dai, W.G. Mao, C. Lu, L. Yang, Y.C. Zhou

PII:

$$
\text { S0257-8972(12)00231-9 }
$$

doi: 10.1016/j.surfcoat.2012.03.050

Reference: $\quad$ SCT 17435

To appear in: $\quad$ Surface \& Coatings Technology

Received date: 3 November 2011

Accepted date: 15 March 2012

Please cite this article as: W.B. Yao, C.Y. Dai, W.G. Mao, C. Lu, L. Yang, Y.C. Zhou, Acoustic emission analysis on tensile failure of air plasma-sprayed thermal barrier coatings, Surface \& Coatings Technology (2012), doi: 10.1016/j.surfcoat.2012.03.050

This is a PDF file of an unedited manuscript that has been accepted for publication. As a service to our customers we are providing this early version of the manuscript. The manuscript will undergo copyediting, typesetting, and review of the resulting proof before it is published in its final form. Please note that during the production process errors may be discovered which could affect the content, and all legal disclaimers that apply to the journal pertain. 


\title{
Acoustic emission analysis on tensile failure of air plasma-sprayed thermal barrier coatings
}
W. B. Yao ${ }^{\text {a,b }}$
C. Y. Dai ${ }^{\mathrm{a}, \mathrm{b}}$
W. G. Mao ${ }^{\mathrm{a}, \mathrm{b}, \mathrm{c}, *}$
C. $\mathrm{Lu}^{\mathrm{d}, *}$
L. Yang ${ }^{\mathrm{a}, \mathrm{b}}$
Y. C. Zhou,

${ }^{a}$ Faculty of Materials, Optoelectronics and Physics, Xiangtan University, Hunan 411105, China

${ }^{\mathrm{b}}$ Key Laboratory of Low Dimensional Materials \& Application Technology, Ministry of Education, Xiangtan University, Hunan 411105, China

${ }^{\mathrm{c}}$ Aeronautical Science and Technology Key Laboratory of Aeronautical Test and Evaluation, Nanchang Hangkong University, Jiangxi 330063, China

${ }^{\mathrm{d}}$ Department of Mechanical Engineering, Curtin University, Western Australia 6845, Australia

\begin{abstract}
An acoustic emission technique was used to monitor the cracking behavior and fracture process of thermal barrier coatings subjected to tensile loading. Acoustic emission signals were extracted and preformed by fast Fourier transform, and their characteristic frequency spectrums and dominant bands were obtained to reveal fracture modes. Three different characteristic frequency bands were confirmed, corresponding to substrate deformation, surface vertical cracking and interface delamination, with the aid of scanning electronic microscopy observations. A map of the tensile failure mechanism of air plasma-sprayed thermal barrier coatings was established. The fracture strength and interfacial shear strength were estimated as
\end{abstract}

\footnotetext{
*Corresponding authors: ssamao@xtu.edu.cn; C.Lu@ curtin.edu.au
} 
$45.73 \pm 3.92 \mathrm{MPa}$ and $20.51 \pm 1.74 \mathrm{MPa}$, respectively, which are well agreement with available results.

Highlights

We established several good correlations between AE data and fracture modes.

The correlations can be utilized to reveal cracking profile and coating failure.

A tensile failure mechanism of coating system was established.

Fracture strength of thermal barrier coating has been obtained by this method.

The method has a large advantage to study the failure of coating/film materials.

Keywords: Thermal barrier coating; Acoustic emission; Fast Fourier transform;

Fracture mode 


\section{Introduction}

To enhance the durability and fuel efficiency, thermal barrier coatings (TBCs) are a commonly used method to provide the thermal resistance in gas turbine engines and other high temperature components ${ }^{[1,2]}$. A TBC system usually consists of ceramic coating, thermally grown oxide, bond coat and substrate. In service, crack nucleation and propagation gradually occurs due to oxidation and mismatch stresses, which eventually results in delamination and spallation of coating ${ }^{[2,3]}$. Therefore, to study failure mechanisms of TBCs, a lot of techniques have been developed such as acoustic emission (AE) ${ }^{[4]}$, digital image correlation ${ }^{[5-7]}$, photoluminescence piezospectroscopy ${ }^{[8-10]}$, and indentation methods ${ }^{[6,11]}$. Among these methods, the AE technique is generally used to identify the evolution of internal and external damage prior to failure in structural and functional materials under loading. Many attempts have been made to correlate AE characteristics with failure mechanisms or modes, such as the statistical analysis of signals and their amplitude distributions ${ }^{[12,13]}$. For example, Ma et al. applied a source inversion processing of AE signals to classify cracking modes of air plasma-sprayed (APS) TBCs during bend tests ${ }^{[14,15]}$. Yang et al. performed the wavelet transform of AE signals to study the failure process of TBCs under tension ${ }^{[16]}$. Trunova et al. reported the degradation evolution and failure mechanisms of APS TBCs during thermal cycling based on the analysis of microstructures and AE signals ${ }^{[17]}$. However, there are few works on the relationships between characteristic frequency spectrums of AE signals and fracture mechanisms of TBCs. In this paper, several such relationships were established between AE signals, 
crack initiation, propagation and fracture behaviors in TBCs subjected to uniaxial tension. In terms of the fast Fourier transform (FFT), the extracted dominant characteristic frequency spectrums of $\mathrm{AE}$ signals were used to correlate with their corresponding failure modes. The reliabilities of identified failure modes were verified by scanning electronic microscopy (SEM) observations. The critical experimental data can be discerned and then applied to deduce the mechanical properties of TBCs, such as coating fracture strength and interfacial shear strength.

\section{Fracture mode and AE signal Analysis}

Among a large number of parameters, AE events and amplitudes have been widely considered as two important parameters in describing the damage evolution in composite materials. Different fracture modes would generate different types of AE signals with various $\mathrm{AE}$ amplitudes ${ }^{[18]}$. AE events and amplitudes are generally analyzed by the Fourier or wavelet analysis ${ }^{[16,19,20]}$. In this paper, AE data were performed by using the discrete Fourier transform to obtain their characteristic frequency spectrums, which ascribe to different fracture sources ${ }^{[21,22]}$. For a discrete AE event $f(t)$ at a given time $t$, it can be decomposed by its Fourier transform $F(w)^{[23]}$, that is

$$
\begin{aligned}
& f(t)=\frac{1}{2 \pi} \int_{-\infty}^{+\infty} F(w) e^{i w t} \mathrm{~d} w \\
& F(w)=\int_{-\infty}^{+\infty} f(t) e^{-i w t} \mathrm{~d} t
\end{aligned}
$$

where $f(t)$ and $F(w)$ are known as a pair of Fourier transforms. $F(w)$ is 
independent of time and represents the frequency composition of a random process. Here, the fast Fourier transform (FFT), an efficient algorithm, was introduced in the discrete Fourier transform. Let us assume that the AE signal $f(t)$ contains $N$ points, the corresponding discrete Fourier sums can be written as ${ }^{[24]}$

$$
\hat{f}(k)=\sum_{n=0}^{N-1} f(n) e^{-\frac{2 \pi k n}{N} j} \quad(0<k<N)
$$

where $\hat{f}(k)$ represents the FFT algorithm. Therefore, the characteristic frequency spectrum and dominant peak of $f(t)$ can be obtained by the FFT. Based on the spectral analysis, different kinds of dominant characteristic frequency peaks are associated with different fracture modes in materials under tensile loading, which can be observed with the aid of SEM.

\section{Experimental}

\subsection{Specimens}

A dog-bone-shaped stainless steel (SUS304) with a cross-section of $10 \times 2 \mathrm{~mm}^{2}$ and a gage length of $80 \mathrm{~mm}$ was selected as substrate. A conventional 8 wt.\% $\mathrm{Y}_{2} \mathrm{O}_{3}-\mathrm{ZrO}_{2}$ (8YSZ) ceramic coat was prepared by APS on NiCoCrAlY, the bond coat deposited on steel substrate ${ }^{[25]}$. The thicknesses of bond and ceramic coats are about 100 and $300 \mu \mathrm{m}$, respectively.

\subsection{Tensile tests}

Tensile tests were carried out at room temperature by a universal testing machine (REGER 2000). The loading rate was controlled as $0.3 \mathrm{~mm} / \mathrm{min}$. The tensile fracture 
process of TBCs was monitored with an $\mathrm{AE}$ measurement system and $\mathrm{AE}$ data were collected in real time by a computer, as illustrated in Fig. 1. Two piezoelectric sensors (PCI-2) were attached on the bottom surface of substrate. AE signals were recorded with a sampling rate of $1 \mathrm{MHz}$ and their thresholds were set at $38 \mathrm{~dB}$ to filter noise.

\section{Results and discussion}

\subsection{Analysis of AE signals}

To find out the relationships between fundamental AE parameters (such as events and amplitudes) and failure sources in a TBC system, the amplitude evolution of AE signals for pure metal substrate and TBC specimens during tensile tests are shown in Fig. 2. The influence of substrate deformation on AE events of TBCs can be clarified based on the AE signal characteristics in pure substrate (see Fig. 2(a)) and their corresponding AE events and stress-strain curve (see Fig. 2(b)). It is obvious that the AE signals are very weak even if substrate undergoes elastic or elastic-plastic deformation during tension. In the case of TBCs, however, the AE signals represent completely different features of crack nucleation and delamination. A typical AE test is shown in Fig. 2(c), which can be approximately divided into five zones. At zone I, there are few AE events with small amplitudes when substrate experiences elastic and elastic-plastic deformation. As the tensile load increases, a burst of AE signals appears and their amplitudes rapidly increase from 38 to $45-70 \mathrm{~dB}$ (zone II), which primarily result from surface vertical cracks. As the tensile stress further increases, the evolution of $\mathrm{AE}$ events drops slowly and then remains at a lower level, but the value of $\mathrm{AE}$ 
amplitudes gradually increases (zone III in Figs. 2(c) and (d)). This is due to the total number of surface vertical microcracks that gradually stops increasing. These cracks start to propagate and link each other to form macrocracks at the coating/bond coat interface. It is of interest to note that, when the tensile stress in substrate approaches to $400 \mathrm{MPa}$ and the corresponding tensile strain equals about $6 \%$, another new kind of AE signals emerges in TBCs and their amplitudes range from 50 to $85 \mathrm{~dB}$ (zone IV in Figs. 2(c) and (d)), which are higher than that in zone II. Moreover, the subsequent SEM observations indicate that delamination and spallation in coating begin to occur during this period. Finally, AE signals become sparse and small when the coating gradually detaches from substrate, as shown by zone V in Fig. 2(d). It is seen that, with the increase of tensile loads, the features of $\mathrm{AE}$ events and amplitudes in different deformation phases can fully reflect the variation of failure modes and damage accumulation in TBCs.

\subsection{AE waveform analysis and fracture modes}

Generally speaking, AE signals include substrate deformation, noise and coating failure. To clarify different fracture sources in TBCs by the AE technique, it is crucial to correlate AE signals with failure modes. As we know, the frequency spectrums of $\mathrm{AE}$ signals are closely related to the characteristics and failure modes of tested

materials ${ }^{[26,27]}$, but are almost independent of failure size and outside load ${ }^{[16,28,29]}$. In the following discussion, an individual AE signal in Fig. 2 was performed by the FFT analysis and its dominant frequency spectrum and peak can be obtained, as shown in 
Fig. 3. Different characteristic frequency peaks (or bands) would correspond to different failure types of a TBC system during tension. Fig. 3(a) is a random AE signal in the time domain extracted from Fig. 2(b) for pure substrate. After the FFT analysis, its frequency spectrum is displayed in Fig. 3(b). The magnitude of an AE characteristic frequency peak locates near $0.14 \mathrm{MHz}$ (type A) for pure substrate. Similarly, in the case of TBCs, a random AE signal with the time domain in zone II of Fig. 2(c) is shown in Fig. 3(c) and its characteristic frequency spectrum is in Fig. 3(d). It is seen that, besides the frequency $0.14 \mathrm{MHz}$ induced by substrate, an extra new sharp frequency band (type B) appears around the range from 0.22 to $0.25 \mathrm{MHz}$. Based on experimental tests and subsequent SEM observations (see inset in Fig. 3(d)), it is mainly attribute to the influence of surface vertical cracks in coating. Using a similar method, a random AE signal in zone IV of Fig. 2(d) was extracted and shown in Fig. 3(e), and its frequency spectrum is in Fig. 3(f). It is of interest to see that another new characteristic frequency band (type C) emerges within the range of 0.08 to $0.1 \mathrm{MHz}$, which is easy to distinguish from the above two characteristic frequency bands (i.e., 0.14 and $0.22-0.25 \mathrm{MHz}$ ). The SEM analysis indicates that the new peak is due to interface cracking or delamination in coating (see inset in Fig. 3(f)). Moreover, we found out that the magnitude of a frequency band $(0.08$ to $0.1 \mathrm{MHz})$ for interface delamination in TBCs is slightly smaller than that of surface vertical cracking, which is similar to previous results ${ }^{[4]}$. Other available experiments also showed that, for a brittle coating/ductile substrate system, vertical cracks firstly appear in coating and propagate towards the ceramic coating/bond coat interface, and 
then deflect into interface cracking or delamination with the increase of tensile stress ${ }^{[30,31]}$. Therefore, the characteristic frequency spectrums and corresponding dominant bands of an AE signal can be obtained after a series of the FFT analysis. According to the distribution of characteristic frequency bands during different deformation phases, the cracking feature and failure type in a TBC system can be evaluated.

\subsection{Failure mechanisms}

Figure 4 shows the evolution of cumulative AE events and applied stress (or strain) in a TBC system during tension. Here, it is worth noting that all data were extracted from Fig. 2(c). It is seen that, in the initial stage with the strain $\varepsilon_{x x}^{s}<1 \%$ in substrate, there are a few AE events, where the dominant characteristic frequency peak is type A $(0.14 \mathrm{MHz})$ due to substrate deformation. At $\varepsilon_{x x}^{s} \approx 1 \%$, the first kind of AE events occurs. When $\varepsilon_{x x}^{s}$ ranges from $1 \%$ to $2.6 \%$, the dominant characteristic frequency bands of $\mathrm{AE}$ events include types $\mathrm{A}$ and $\mathrm{B}(0.22-0.25 \mathrm{MHz})$, which is attributed to surface vertical cracks in coating, as shown in Figs. 3(c) and (d). In the case of $2.6 \%<$ $\varepsilon_{x x}^{s}<7.1 \%$, AE signals involve three completely different events, and their dominant characteristic frequency bands contain types $\mathrm{A}, \mathrm{B}(0.22 \sim 0.25 \mathrm{MHz})$ and $\mathrm{C}(0.08$ to $0.1 \mathrm{MHz}$ ), as shown in Figs. 3(e) and (f). The mixed cracking region consists of surface vertical cracks and interface delamination. When $\varepsilon_{x x}^{s}$ is equal to about $7.1 \%$, the number of surface vertical cracks stops increasing and remains in a saturation state. Furthermore, when $\varepsilon_{x x}^{s}>7.1 \%$, AE signals mainly involve two different events and their corresponding characteristic frequency bands are types A and C. It implies that, 
in this region, the dominant crack type is interface delamination. If $\varepsilon_{x x}^{s}$ increases up to $9 \%$, the coating begins to detach from bond coat.

The evolution of two types of AE events with $\varepsilon_{x x}^{s}$ for surface vertical cracks and interface delamination during tension can be described by the following function

$$
N\left(\varepsilon_{x x}^{s}\right)=N_{c o n}\left\{1-\exp \left[-A\left(\varepsilon_{x x}^{s}-\varepsilon_{x x, c}^{s}\right)^{\alpha}\right]\right\}
$$

where $N\left(\varepsilon_{x x}^{s}\right)$ is the cumulative number of $\mathrm{AE}$ events, $N_{c o n}$ is the total (or stable) number, $\varepsilon_{x x}^{s}$ is the applied strain on substrate, and $\varepsilon_{x x, c}^{s}$ is the critical longitudinal strain in substrate when a crack in coating occurs. $A$ and $\alpha$ are fitting constants, which are dependent on a coating system. Here, $A$ and $\alpha$ are equal to 0.42 and 1.96 for vertical cracks, and 2.71 and 7.91 for interface delamination, respectively. Such a fitted equation is useful for non-destructive measurements and the life prediction of APS TBCs.

\subsection{Evaluation of mechanical properties}

Based on Figs. 2(c) and (d), the critical fracture time is about $140 \mathrm{~s}$, at which the burst of AE signals occurs. It indicates the formation of the first surface vertical crack in coating. The corresponding critical strain $\varepsilon_{x x, c}^{s}$ is $0.87 \pm 0.04 \%$. To estimate the stress distribution in top ceramic coat at this moment, TBCs are assumed to be homogeneous and isotropic. Stress in the coating can be considered as plane stress. The parameters of bond coat are similar to that in substrate, which are approximately regarded as a layer. Thus, the constitutive equations of TBCs can be represented as ${ }^{[32]}$

$$
\sigma_{x x}^{c}=\frac{1-\boldsymbol{v}^{c} \boldsymbol{v}^{s}}{1-\boldsymbol{\gamma}^{c^{2}}} E^{c} \cdot \varepsilon_{x x}^{s}+\sigma_{r}^{c}
$$




$$
\sigma_{y y}^{c}=\frac{v^{c}-v^{s}}{1-\boldsymbol{\ell}^{c^{2}}} E^{c} \cdot \varepsilon_{x x}^{s}+\sigma_{r}^{c}
$$

where superscripts $c$ and $s$ denote coating and substrate, respectively. $\sigma_{r}^{c}$ is the average residual stress in coating that equals about $-40 \mathrm{MPa}$ for as-received APS TBCs ${ }^{[33,34]} . E^{c}$ and $v^{c}$ are, respectively, Young's modulus and Poisson's ratio of coating, and $v^{s}$ is Poisson's ratio of substrate. According to nanoindentation tests, $E^{c}$ of as-received APS 8YSZ coating is about $10 \mathrm{GPa}^{[35]}$, and $v^{c}$ and $v^{s}$ are 0.1 and 0.3 , respectively ${ }^{[36]}$. Thus, the fracture strength $\sigma_{x x, c}^{c}$ of TBCs can be evaluated as $45.73 \pm 3.92 \mathrm{MPa}$, which agrees well with available experimental results ${ }^{[37,38]}$.

As the tensile stress increases, the interface shear stress $\tau_{i}$ between top coating and bond coat exceeds its shear strength $\tau_{c}$ and results in interface delamination. Chen et al. used a quarter-elliptical approximation to evaluate the interfacial shear stress distribution of a brittle coating-metal system under tensile strain ${ }^{[39]}$. Fig. 5 shows an antisymmetric distribution of interfacial shear stress around a small segment of the cracked coating. A correlation between $\tau_{c}$ and $\sigma_{x x, c}^{c}$ can be written as ${ }^{[39]}$

$$
\tau_{c}=\frac{4 h \sigma_{x x, c}^{c}}{\lambda_{0}(\pi+4)}
$$

where $h$ is the coating thickness. $\lambda_{0}$ is equal to $\lambda / 2$ with $\lambda$ being the crack spacing when surface vertical cracks approach to saturation, as illustrated in Fig. 6. In our tests, $\lambda$ ranges from 0.69 to $0.82 \mathrm{~mm}$ by SEM observations. When $\varepsilon_{x x}^{s}$ is about $3.5 \%$, there is no more $\mathrm{AE}$ events of vertical cracks and interface delamination gradually occurs (see Fig. 4). Using these data, the shear strength $\tau_{c}$ can be evaluated as $20.51 \pm 1.74 \mathrm{MPa}$, which is similar to the previous results obtained by 
finite element analysis and experimental tests ${ }^{[5,40]}$.

\section{Conclusions}

Cracking and failure behaviors of APS TBCs were studied by using uniaxial tensile tests coupled with non-destructive AE monitoring. AE signals were analyzed by FFT and their corresponding dominant frequency bands were applied to predict failure modes of TBCs with the aid of SEM observations. The main conclusions can be summarized as follows:

(1) The dominant frequency bands for surface vertical cracks and interface delamination of as-received APS TBCs are $0.22-0.25 \mathrm{MHz}$ and $0.08-0.1 \mathrm{MHz}$, respectively. According to the dominant frequency bands and SEM observations, the correlations between $\mathrm{AE}$ signals, fracture types and failure mechanisms can be successfully established.

(2) Fracture strength of ceramic coat and interfacial shear strength of TBCs were evaluated as $45.73 \pm 3.92 \mathrm{MPa}$ and $20.51 \pm 1.74 \mathrm{MPa}$, which are well consistent with available results.

\section{Acknowledgments}

This work has been supported by the Open Fund of Aeronautical Science and Technology Key Laboratory of Aeronautical Test and Evaluation of Nanchang Hangkong University (No. HK2009005), the Young Teacher Fund of Ministry of Education (No. 200805301023), the Foundation of Teaching and Research Equipment Transformation Development Project (No. SG2009001), the National Natural Science 
Foundations of China (Nos. 11102177, 51172192 and 11002122), the Natural Science Foundation of Hunan Province for Innovation Group (No. 09JJ7004), and the Program for Changjiang Scholars and Innovative Research Team in University (No. IRT1080).

\section{References}

[1] A.G. Evans, D.R. Mumm, J.W. Hutchinson, G.H. Meier, F.S. Pettit, Prog. Mater. Sci., 46 (2001) 505-553.

[2] N.P. Padture, M. Gell, E.H. Jordan, Science, 296 (2002) 280-284.

[3] J.L. Beuth, S.H. Narayan, Int. J. Solids. Struct., 33 (1996) 65-78.

[4] S. Nishinoiri, M. Enoki, K. Tomita, Sci. Technol. Adv. Mater., 4 (2003) 623-631.

[5] D.J. Wu, W.G. Mao, Y.C. Zhou, C. Lu, Appl. Surf. Sci., 257 (2011) 6040-6043.

[6] C. Pfeiffer, E. Affeldt, M. Göken, Surf. Coat. Technol., 205 (2011) 3245-3250.

[7] N. Zotov, M. Bartsch, G. Eggeler, Surf. Coat. Technol., 203 (2009) 2064-2072.

[8] M.S. Majewski, C. Kelley, W. Hassan, W. Brindley, E.H. Jordan, M.W. Renfro, Surf. Coat. Technol., 205 (2011) 4614-4619.

[9] X. Wang, A. Atkinson, L. Chirivì, J.R. Nicholls, Surf. Coat. Technol., 204 (2010) $3851-3857$.

[10] C. Rinaldi, L.D. Maria, M. Mandelli, J. Eng. Gas. Turb. Power., 132 (2010) 114501-114504.

[11] Y. Yamazaki, S. Kuga, T. Yoshida, Acta Metall. Sin. (Engl. Lett.), 24 (2011) 109-117.

[12] Y. Xu, B.G. Mellor, Surf. Coat. Technol., 205 (2011) 5478-5482.

[13] C. Lu, Y.-W. Mai, Y.-G. Shen, Phys. Rev. E, 72 (2005) 027101.

[14] X.Q. Ma, S. Cho, M. Takemoto, Surf. Coat. Technol., 139 (2001) 55-62.

[15] X.Q. Ma, M. Takemoto, Mater. Sci. Eng., A, 308 (2001) 101-110.

[16] L. Yang, Y.C. Zhou, W.G. Mao, C. Lu, Appl. Phys. Lett., 93 (2008) 231906.

[17] O. Trunova, P. Bednarz, R. Herzog, T. Beck, L. Singheiser, Int. J. Mater. Res., 99 
(2008) 1129-1135.

[18] D. Dalmas, S. Benmedhakène, H. Kébir, C. Richard, A. Laksimi, J.M. Roleandt, Surf. Coat. Technol., 173 (2003) 130-143.

[19] A. Gallego, J.F. Gil, E. Castro, R. Piotrkowski, Surf. Coat. Technol., 201 (2007) 4743-4756.

[20] W.G. Mao, D.J. Wu, W.B. Yao, M. Zhou, C. Lu, J. Appl. Phys., 110 (2011) 084903.

[21] M. Giordano, A. Calabro, C. Esposito, A. D'Amore, L. Nicolais, Compos. Sci. Technol., 58 (1998) 1923-1928.

[22] C.R. Ramirez-Jimenez, N. Papadakis, N. Reynolds, T.H. Gan, P. Purnell, M. Pharaoh, Compos. Sci. Technol., 64 (2004) 1819-1827.

[23] X. Li, Int. J. Mach. Tool. Manu., 42 (2002) 157-165.

[24] M. Martin E, J. Algebra., 324 (2010) 282-312.

[25] W.G. Mao, C.Y. Dai, Y.C. Zhou, Q.X. Liu, Surf. Coat. Technol., 201 (2007) 6217-6227.

[26] C. Patapy, A. Proust, D. Marlot, M. Huger, T. Chotard, J. Eur. Ceram. Soc., 30 (2010) 3093-3101.

[27] Y.Z. Pappas, A. Kontsos, T.H. Loutas, V. Kostopoulos, NDT \& E Int., 37 (2004) $389-401$.

[28] S.-H. Seong, S. Hur, J.-S. Kim, J.-T. Kim, W.-M. Park, U.-C. Lee, S.-K. Lee, Ann. Nucl. Energy, 32 (2005) 479-492.

[29] L. Yang, Y.C. Zhou, C. Lu, Acta. Mater., 59 (2011) 6519-6529.

[30] W.G. Mao, C.Y. Dai, L. Yang, Y.C. Zhou, Int. J. Fracture., 151 (2008) 107-120.

[31] B.Q. Yang, K. Zhang, G.N. Chen, G.X. Luo, J.H. Xiao, Surf. Eng., 24 (2008) $332-336$.

[32] T. Ganne, J. Crépin, S. Serror, A. Zaoui, Acta. Mater., 50 (2002) 4149-4163.

[33] W.G. Mao, Y.C. Zhou, L. Yang, X.H. Yu, Mech. Mater., 38 (2006) 1118-1127.

[34] Q. Chen, W.G. Mao, Y.C. Zhou, C. Lu, Appl. Surf. Sci., 256 (2010) 7311-7315.

[35] W.G. Mao, Q. Chen, C.Y. Dai, L. Yang, Y.C. Zhou, C. Lu, Surf. Coat. Technol., 204 (2010) 3573-3577. 
[36] Y.C. Zhou, T. Hashida, Int. J. Solids. Struct., 38 (2001) 4235-4264.

[37] D. Schwingel, R. Taylor, T. Haubold, J. Wigren, C. Gualco, Surf. Coat. Technol., 108-109 (1998) 99-106.

[38] Y. Yamazaki, A. Schmidt, A. Scholz, Surf. Coat. Technol., 201 (2006) 744-754.

[39] B.F. Chen, J. Hwang, I.F. Chen, G.P. Yu, J.H. Huang, Surf. Coat. Technol., 126 (2000) 91-95.

[40] P.F. Zhao, C.A. Sun, X.Y. Zhu, F.L. Shang, C.J. Li, Surf. Coat. Technol., 204 (2010) 4066-4074. 


\section{Figure captions}

Fig. 1. (Color Online) Schematic image of the tensile test device with an AE system.

Fig. 2. (Color Online) Evolution of $\mathrm{AE}$ amplitudes and events, testing time and external stress-strain during tensile tests in $(a, b)$ pure substrate and $(c, d)$ as-received TBCs.

Fig. 3. (Color Online) Representative AE signals (a, c and e) extracted from different tensile phases in Fig. 2 and their corresponding characteristic frequency spectrums (b, d and f) after FFT. SEM patterns (see insets) are relevant fracture modes.

Fig. 4. (Color Online) Map of the tensile failure mechanism in an as-received APS TBC system.

Fig. 5. (Color Online) Schematic of the shear lag model for a segmented coating.

Fig. 6. (Color Online) SEM image of surface multiple cracks, where the tensile strain is about $3.5 \%$. 


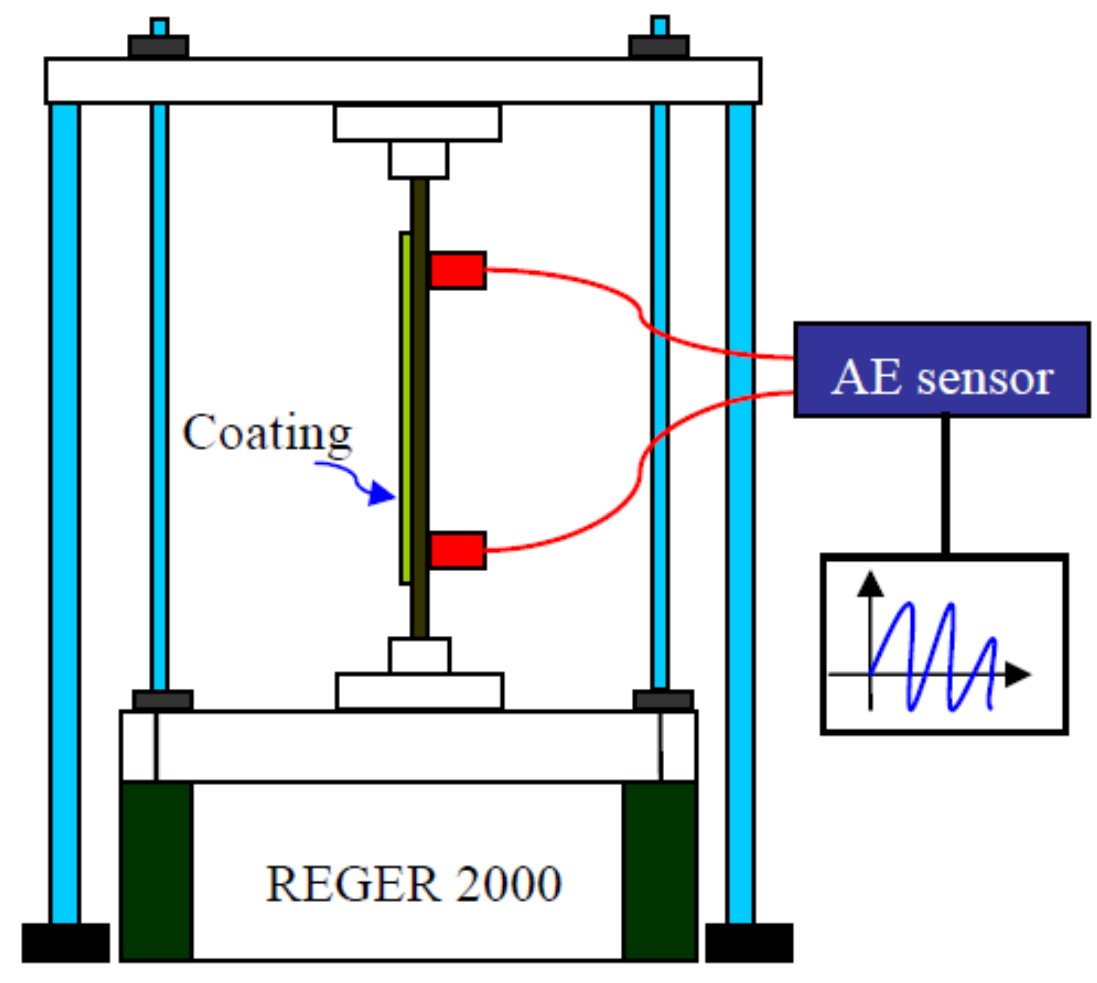

Fig. 1 

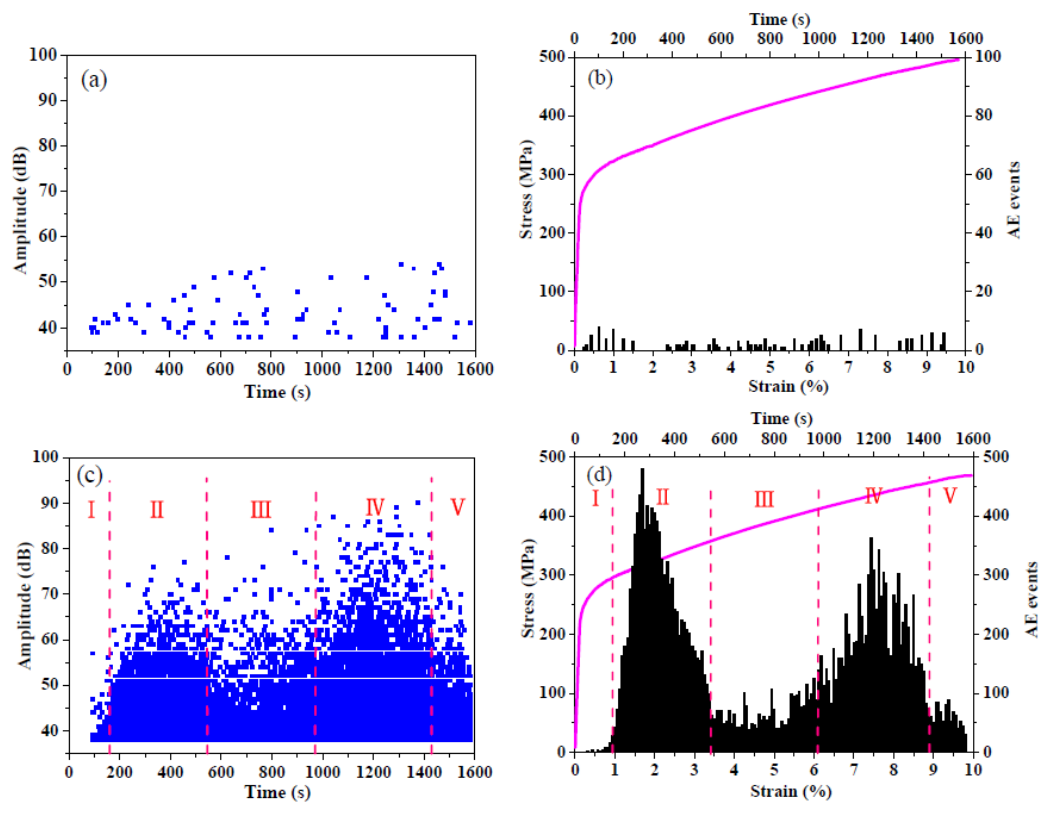

Fig. 2 

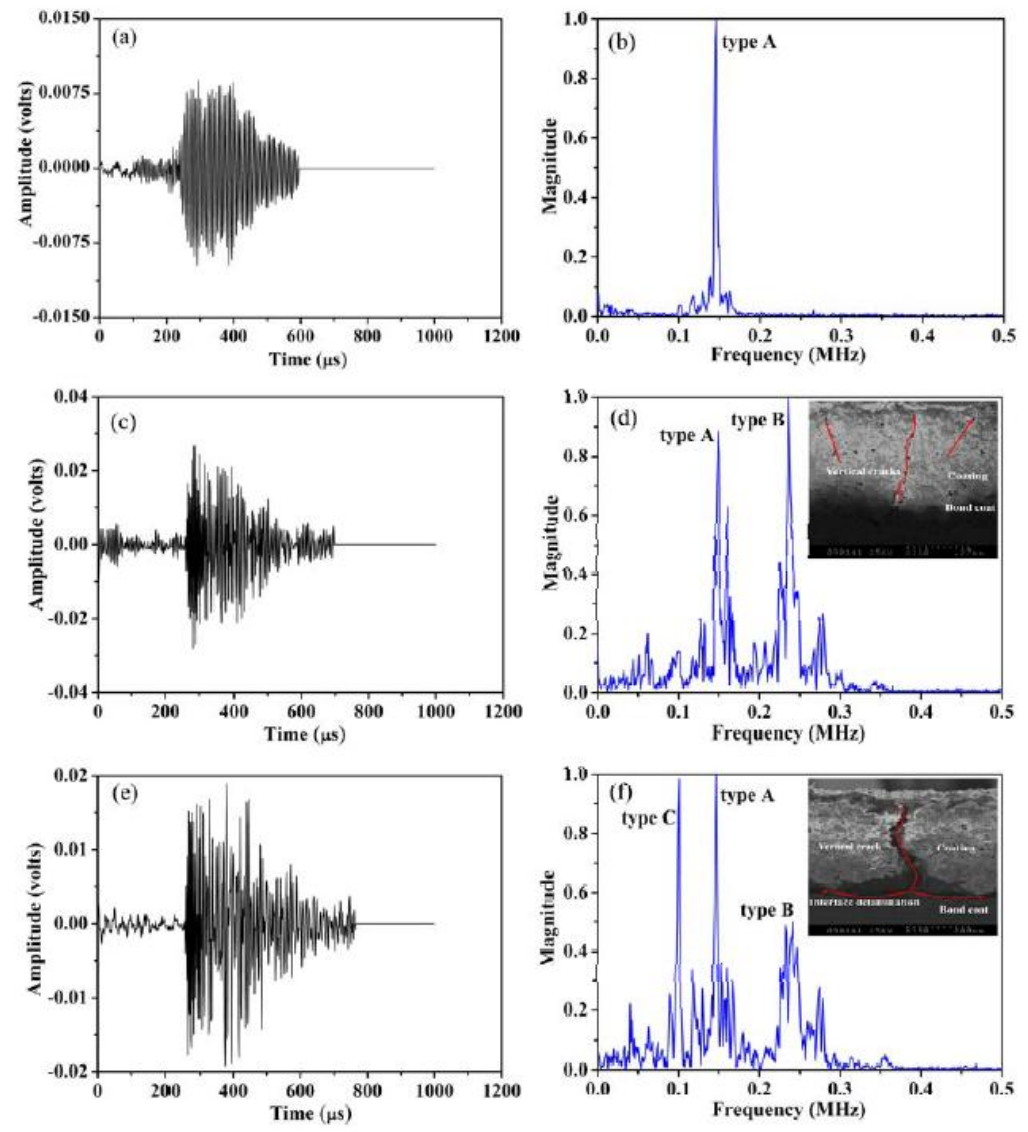

Fig. 3 


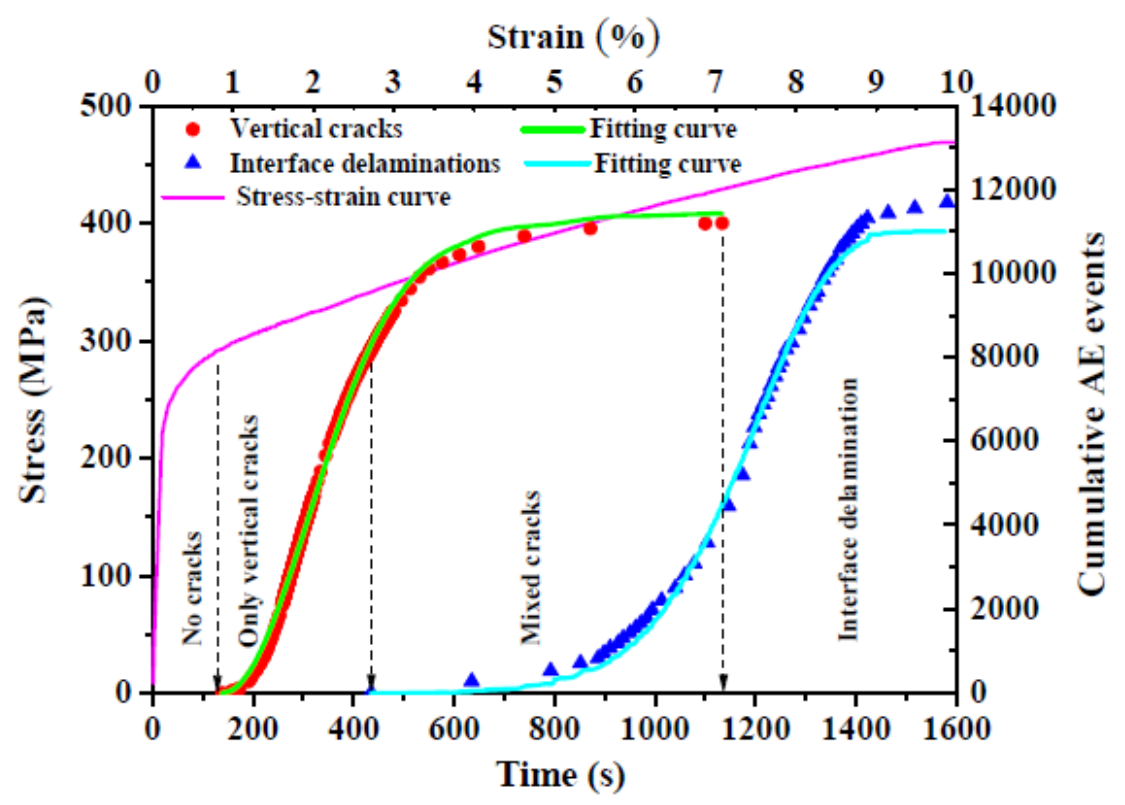

Fig. 4 


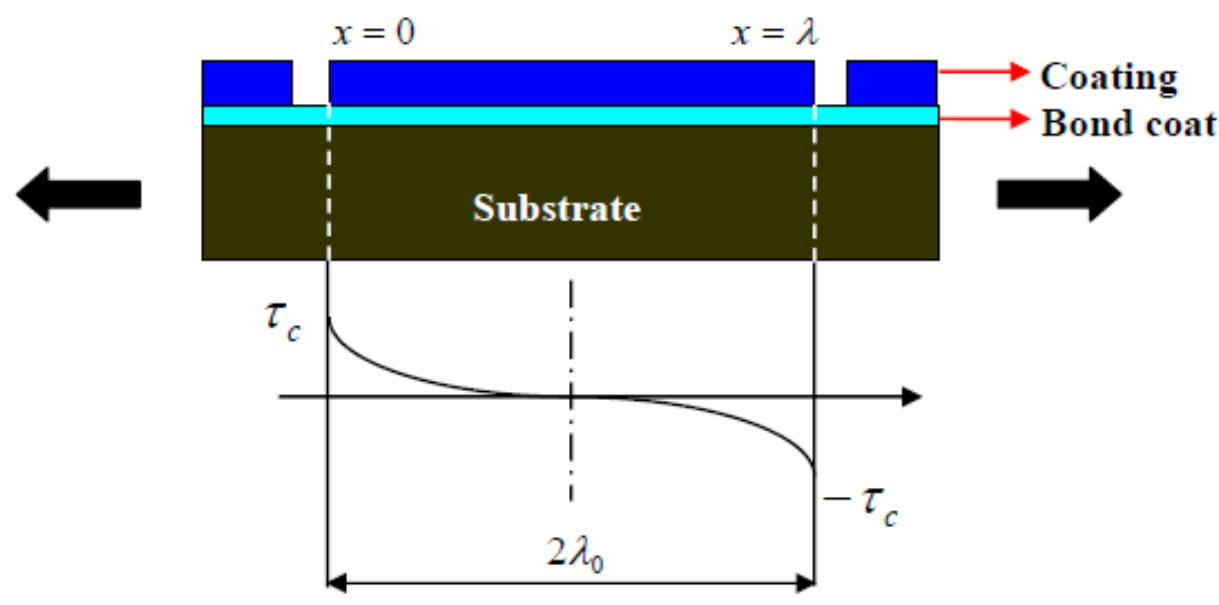

Fig. 5 


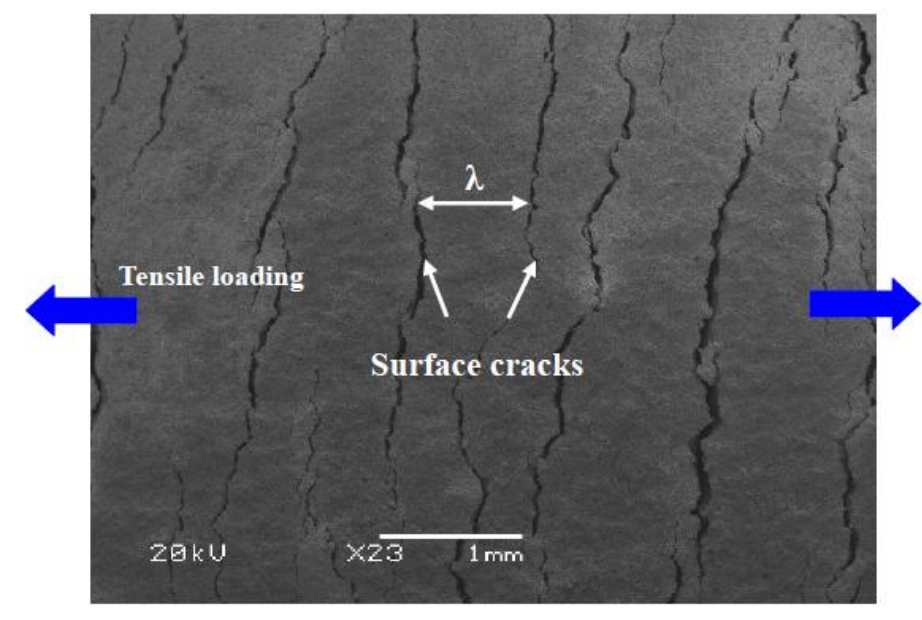

Fig. 6 